\title{
Alcohol Intake Modulates the Effect of a Polymorphism of the Cholesteryl Ester Transfer Protein Gene on Plasma High Density Lipoprotein and the Risk of Myocardial Infarction
}

\author{
Frédéric Fumeron, * Dina Betoulle, * Gérald Luc, $\$ \$$ Isabelle Behague, "Sylvain Ricard, " Odette Poirier, "Riadh Jemaa, * \\ Alun Evans, " Dominique Arveiler, ** Pedro Marques-Vidal," Jean-Marie Bard," Jean-Charles Fruchart," \\ Pierre Ducimetière, ${ }^{\$ S}$ Marian Apfelbaum, ${ }^{*}$ and François Cambien" \\ *INSERM U286, Faculté de Médecine Xavier Bichat, 75018 Paris, France; ${ }^{\ddagger}$ SERLIA-INSERM U325 and ${ }^{\S}$ MONICA Project-Lille, \\ Institut Pasteur, 59019 Lille, France; "INSERM SC7, 75005 Paris, France; ' ${ }^{M O N I C A}$ Project-Belfast, The Queen University of Belfast,

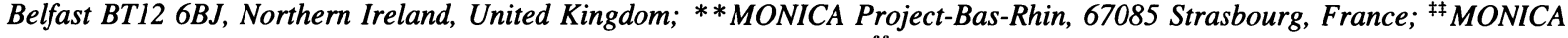 \\ Project-Haute-Garonne, CHU Purpan, 31059 Toulouse, France; and ${ }^{8}$ INSERM U258, Hôpital Broussais, 75674 Paris, France
}

\begin{abstract}
A polymorphism of the CETP gene (CETP/TaqIB) with two alleles $B 1(60 \%)$ and $B 2(40 \%)$ has been investigated in relation to lipid variables and the risk of myocardial infarction in a large case-control study (ECTIM) of men aged 25-64. No association was observed between the polymorphism and LDL or VLDL related lipid variables. Conversely, B2 carriers had reduced levels of plasma CETP ( $P$ $<0.0001)$ and increased levels of HDL cholesterol $(P<$ 0.0001 ) and of other HDL related lipid variables. The effects of the polymorphism on plasma CETP and HDL cholesterol were independent, suggesting the presence of at least two functional variants linked to B2. A search for these variants on the coding sequence of the CETP gene failed to identify them. The effect of $B 2$ on plasma HDL cholesterol was absent in subjects drinking $<25$ grams/d of alcohol but increased commensurably, with higher values of alcohol consumption (interaction: $\boldsymbol{P}<0.0001$ ). A similar interaction was not observed for plasma CETP. The odds-ratio for myocardial infarction of B2 homozygotes decreased from 1.0 in nondrinkers to 0.34 in those drinking 75 grams/d or more. These results provide the first demonstration of a geneenvironment interaction affecting HDL cholesterol levels and coronary heart disease risk. (J. Clin. Invest. 1995. 96:1664-1671.) Key words: alcohol drinking • carrier proteins $•$ high density lipoprotein cholesterol $\bullet$ myocardial infarction - restriction fragment length polymorphisms
\end{abstract}

Address correspondence to François Cambien, M.D., INSERM SC7, 17 rue du Fer à Moulin, 75005 Paris, France. Phone: 33-1-43-31-72 09; FAX: 33-1-47-07-17-41.

Received for publication 8 February 1995 and accepted in revised form 24 May 1995

1. Abbreviations used in this paper: CETP, cholesteryl ester transfer protein; CHD, coronary heart disease; ECTIM, Etude Cas-Témoin de l'Infarctus du Myocarde; Lp, lipoprotein particle; MI, myocardial infarction.

J. Clin. Invest.

(C) The American Society for Clinical Investigation, Inc.

0021-9738/95/09/1664/08 \$2.00

Volume 96, September 1995, 1664-1671

\section{Introduction}

Plasma high density lipoprotein (HDL) cholesterol is negatively related to the risk of coronary heart disease $(\mathrm{CHD})^{1}(1,2)$ and alcohol consumption is associated with a decreased incidence of CHD, apparently through an increase in plasma HDL cholesterol (3). Part of the relation between alcohol consumption and HDL cholesterol is mediated by the effect of alcohol on cholesteryl ester transfer protein (CETP) activity $(4,5)$. In alcoholics, CETP activity is low and increases after ethanol withdrawal (6-8); moreover, moderate alcohol intake induces a decrease of CETP activity (9). The role of CETP is to promote transfer of cholesteryl ester from the core of HDL particles to triglyceride-rich lipoproteins, in exchange for triglycerides (4, 5 ). Recent data show that an increased transfer of cholesteryl esters from HDL to very low density lipoproteins (VLDL) and low density lipoproteins (LDL) may characterize patients with established coronary artery disease (10). An increased CETP activity by reducing the cholesterol content of HDL relative to LDL and VLDL could thus contribute to an increased risk of CHD. Furthermore, major deficiencies of the CETP gene are associated with high levels of HDL cholesterol (11-13) and possibly increased life span (12). A frequent TaqI polymorphism (CETP/TaqIB) of the CETP gene is associated with plasma HDL cholesterol, individuals carrying the B2 allele (absence of cutting site) having the highest levels of HDL cholesterol (14-18).

Since plasma HDL cholesterol and other related parameters, including apolipoprotein (apo) AI and lipoprotein particle (Lp) $\mathrm{AI}$, as well as alcohol consumption are important discriminant factors between cases with myocardial infarction (MI) and controls in the ECTIM study (19), the CETP gene was considered as a possible candidate for MI and its polymorphism was investigated. Possible associations between CETP/TaqIB and different plasma lipid parameters (including CETP mass) were investigated in control subjects and the distribution of CETP genotypes was compared between cases and controls. Each analysis was also performed according to alcohol consumption. Finally, the CETP gene was screened for variants linked to the CETP/ TaqIB polymorphism.

\section{Methods}

Study populations and sampling of cases and controls. Study populations and sampling of cases and controls have been described elsewhere 


\begin{tabular}{|c|c|c|c|c|}
\hline Position & Amplimers $\left(5^{\prime}-3^{\prime}\right)$ & Size & Annealing temperature & Allele-specific oligonucleotide $\left(5^{\prime}-3^{\prime}\right)^{*}$ \\
\hline \multicolumn{5}{|c|}{$b p$} \\
\hline Intron $1^{\ddagger}$ & $\begin{array}{l}\text { U:CACTAGCCCAGAGAGAGGAGTGCC } \\
\text { L:CTGAGCCCAGCCGCACACTAAC }\end{array}$ & 535 & $60^{\circ} \mathrm{C}$ & - \\
\hline Intron $7^{\S}$ & $\begin{array}{l}\text { U:ACTGGTCAGGGGCTCATTGT } \\
\text { L:GGCTCCCACTGCTGTCTTCT }\end{array}$ & 433 & $60^{\circ} \mathrm{C}$ & $\begin{array}{l}1^{\| \prime: G G T G A G T G C G T T T C T G T ~} \\
2^{\|}: \text {GGTGAGTGTGTTCTGT }\end{array}$ \\
\hline Intron 12 & $\begin{array}{l}\text { U:GGCCAATGGAGGGTCAAAT } \\
\text { L:TGGTCTGGTTGCCTGATTTC }\end{array}$ & 177 & $58^{\circ} \mathrm{C}$ & $\begin{array}{l}\text { 1:TATCATCG } \underline{T T T T T T A T} \\
\text { 2:TATCATCG } \underline{T T T T T T A T}\end{array}$ \\
\hline Intron 14 & $\begin{array}{l}\text { U:CATCTGCCTTGTGGGTCACT } \\
\text { L:TGAAATGGGAAGCTCTGTCA }\end{array}$ & 192 & $65^{\circ} \mathrm{C}$ & $\begin{array}{l}\text { 1:CATGTCTCGTAAGTGTG } \\
\text { 2:CATGTCTCATAAGTGTG } \\
2^{\prime}: \text { TGTCTCGTTAAGTGTGG }\end{array}$ \\
\hline Exon 15 & $\begin{array}{l}\text { U:AGGGCTGACTGGGGCTCTGT } \\
\text { L:GAATCCTGTCTGGGCCTCTC }\end{array}$ & 179 & $65^{\circ} \mathrm{C}$ & $\begin{array}{l}\text { 1:CCTCTTCGACATCATCA } \\
\text { 2:CCTCTTCG } \underline{C A T C A T C A}\end{array}$ \\
\hline Intron 16 & $\begin{array}{l}\text { U:TCGCCCCTCTCTCCTACTGC } \\
\text { L:AGAAGGACTCCGCAGCTCTT }\end{array}$ & 302 & $55^{\circ} \mathrm{C}$ & $\begin{array}{l}\text { 1:TTCCACCACGCTGGAGG } \\
\text { 2:CCTCCAGCATGGTGGAA }\end{array}$ \\
\hline
\end{tabular}

" 1 corresponds to the more frequent allele, 2 to the less frequent allele. ${ }^{\ddagger}$ The amplification product was digested by TaqI, the lengths of the fragments obtained were 174 and $361 \mathrm{bp}$. The amplification product was digested by DpnI before single-strand conformation polymorphism analysis, the lengths of the fragments obtained were 161 and $274 \mathrm{bp}$. * The melting temperature used for hybridization was calculated by adding $4^{\circ} \mathrm{C}$ for each $\mathrm{G}$ or $\mathrm{C}$ and $2^{\circ} \mathrm{C}$ for each $\mathrm{T}$ or $\mathrm{A}$ and subtracting $5^{\circ} \mathrm{C}$ from the total. The washing temperature was melting temperature minus $3^{\circ} \mathrm{C}$.

(19). Briefly, in the ECTIM study, cases were recruited from WHOMONICA registers (20) from Belfast (Northern Ireland), Lille (Northern France), Strasbourg (Eastern France), and Toulouse (Southwestern France). Male patients aged 25-64 who survived an MI (MONICA category I) were eligible. Male age-matched controls were randomly recruited from the same areas. All participants were white Europeans. For the present analysis, all controls with CHD (prevalent cases in the random samples) were excluded. Information on CETP/TaqIB genotype, alcohol consumption, and plasma HDL cholesterol was available from 608 patients and 724 controls (CETP/TaqIB genotype could be obtained for all but one subject). For the present analysis, focused on HDL related lipid variables, the reported results include subjects receiving lipid-lowering drugs (19); however, consistency of the results was also checked after exclusion of subjects treated with lipid-lowering drugs.

Informed consent was obtained from the subjects and their family doctors. A set of questionnaires was completed which included details of personal history, presence of disease, drug intake (not including dose), cigarette smoking, and alcohol consumption. Patients with MI were interviewed on their consumption of alcohol and cigarettes before MI. A blood sample of $20 \mathrm{ml}$ was obtained from all subjects in the fasting state; in patients, blood was taken 3-9 mo after the MI.

Alcohol consumption for a typical week was obtained by interview using a questionnaire describing standard doses of each alcoholic beverage. The translation in grams per day was done automatically by computer. For the analysis reported here, alcohol consumption was stratified in five classes: $0,>0<25, \geq 25<50, \geq 50<75, \geq 75 \mathrm{grams} / \mathrm{d}$.

Lipid-related analyses. The assays for measuring lipoprotein parameters and a detailed analysis of lipid variables in the ECTIM study have already been reported (19). CETP mass was measured from frozen samples stored at $-80^{\circ} \mathrm{C}$ by two-site immunoenzymatic assay (21) in a large subgroup of the ECTIM study, 564 controls ( $78 \%$ ) and 425 cases $(70 \%)$. Missing measurements are the consequence of transportation or storage problems.

Genetic analyses. Genomic DNA was prepared from white blood cells by phenol extraction. Fragments encompassing the polymorphic sites were amplified by PCR (22). Each amplification was performed using $500 \mathrm{ng}$ of genomic DNA in a volume of $50 \mu$ l containing 50 pmol of each primer (Table I), $200 \mu \mathrm{M}$ dNTPs, $1.5 \mathrm{mM} \mathrm{MgCl}_{2}$, and 0.2 $\mathrm{U}$ of Taq polymerase (Appligene, Illkirch, France). The PCR reaction consisted in 30 cycles of $30 \mathrm{~s}$ of denaturation at $94^{\circ} \mathrm{C}, 30 \mathrm{~s}$ of annealing at appropriate temperature (Table $\mathrm{I}$ ), and $1 \mathrm{mn}$ elongation at $72^{\circ} \mathrm{C}$. To detect the CETP/TaqIB polymorphism, 10- $\mu \mathrm{l}$ aliquots were digested with $5 \mathrm{U}$ of TaqI at $65^{\circ} \mathrm{C}$ for $3 \mathrm{~h}$.

Overlapping fragments of the entire coding region and $387 \mathrm{bp}$ of the 5' flanking region of the CETP gene were amplified by PCR and submitted to single-strand conformation polymorphism analysis (23) according to a strategy that we have formerly used to explore the apolipoprotein $B$ gene (24). Among the 10 individuals selected for this analysis, 7 had high plasma HDL cholesterol levels and were homozygous for the less frequent CETP/TaqIB allele (B2) and 3 had low plasma HDL cholesterol levels and were homozygotes for the more frequent allele (B1). Three intronic variants were identified by singlestrand conformation polymorphism and sequencing (25): $\mathrm{C} \rightarrow \mathrm{T}$ at position +8 of intron 7 (CETP IN7 $\mathrm{C} \rightarrow \mathrm{T}$ ); $\mathrm{C} \rightarrow \mathrm{T}$ in intron 12, 14 bp before exon 13 (CETP IN12 $\mathrm{C} \rightarrow \mathrm{T}$ ), and $\mathrm{G} \rightarrow \mathrm{A}$ in intron 16, $84 \mathrm{bp}$ after the stop codon (CETP IN16 G $\rightarrow$ A). Furthermore, three polymorphic sites identified by Inazu et al. (26) were also investigated: two in intron 14: $\mathrm{G} \rightarrow \mathrm{A}, 1 \mathrm{bp}$ after exon 13 (CETP IN14A) and an insertion of a T, 3 bp after exon 13 (CETP IN14T), and one in exon 15: a $A \rightarrow G$ affecting codon 442 (CETP D442G).

All polymorphisms, except CETP/TaqIB, were analyzed in the ECTIM study by allele-specific oligonucleotide hybridization $(24,27)$, the probes used and assay conditions are provided in Table $\mathrm{I}$.

Statistical analysis. For most analyses involving genotypic data, alleles were coded $0,1,2$ according to the number of the less frequent allele. This ordinal $0,1,2$ variable was used to test an allele-dose linear effect, which is equivalent to assuming codominance of the genetic effect. Alcohol consumption was coded as an ordinal 0, 1, 2, 3, 4 variable for consumptions of $0,>0<25, \geq 25<50, \geq 50<75$, $\geq 75$ grams/d, respectively.

Data were analyzed using the SAS statistical software (SAS Institute Inc., Cary, NC). Lipid and lipoprotein levels were compared between genotypes by ANOVA or regression analysis when testing a dose effect. When investigating the effect of genotypes and alcohol consumption on plasma HDL cholesterol and CETP, a regression model was used where 


\begin{tabular}{|c|c|c|c|c|c|c|c|c|}
\hline & \multirow{2}{*}{\multicolumn{6}{|c|}{ CETP/TaqIB genotypes }} & \multicolumn{2}{|c|}{ Test of linear trend* adjusted on: } \\
\hline & & & & & & & & Population and \\
\hline & \multicolumn{2}{|c|}{11} & \multicolumn{2}{|c|}{12} & \multicolumn{2}{|c|}{22} & Population & CETP level \\
\hline$n$ & \multicolumn{2}{|c|}{258} & \multicolumn{2}{|c|}{346} & \multicolumn{2}{|c|}{120} & & \\
\hline Age & 53.1 & $(8.9)^{\ddagger}$ & 52.7 & $(8.2)$ & 53.7 & (8.4) & NS & NS \\
\hline Body mass index $\left(\mathrm{kg} / \mathrm{m}^{2}\right)$ & 26.5 & (3.9) & 26.4 & (3.7) & 26.3 & (3.9) & NS & NS \\
\hline Alcohol (grams/d) & 39.6 & (41.9) & 40.0 & $(40.9)$ & 43.8 & $(45.5)$ & NS & NS \\
\hline Cigarettes $(n / \mathrm{d})$ & 5.2 & $(9.9)$ & 6.2 & (11.4) & 4.8 & $(9.5)$ & NS & NS \\
\hline LDL cholesterol $(\mathrm{mg} / \mathrm{dl})$ & 152.2 & (35.6) & 155.9 & (43.9) & 151.9 & (34.9) & NS & NS \\
\hline Triglycerides (mg/dl) & 155.7 & (124.3) & 154.3 & (91.9) & 177.1 & $(211.3)$ & NS & NS \\
\hline HDL cholesterol (mg/dl) & 49.5 & $(12.5)$ & 51.2 & (14.8) & 56.8 & $(17.3)$ & $P<0.0001$ & $P<0.002$ \\
\hline apoAI (mg/dl) & 142.2 & $(23.5)$ & 147.7 & (26.7) & 156.2 & $(29.1)$ & $P<0.0001$ & $P<0.0005$ \\
\hline apoAII (mg/dl) & 34.5 & $(8.4)$ & 36.2 & $(9.0)$ & 38.7 & (11.1) & $P<0.0001$ & $P<0.0005$ \\
\hline LpAI (mg/dl) & 46.2 & (12.5) & 48.2 & (14.1) & 52.1 & (15.6) & $P<0.0002$ & $P<0.0005$ \\
\hline LpAI:AII (mg/dl) & 80.2 & $(17.1)$ & 81.0 & (18.9) & 86.0 & (20.7) & $P<0.02$ & $P<0.05$ \\
\hline CETP $(\mathrm{mg} / \mathrm{dl})^{8}$ & 0.22 & $(0.109)$ & 0.21 & $(0.102)$ & 0.16 & $(0.067)$ & $P<0.0001$ & - \\
\hline
\end{tabular}

${ }^{\ddagger}$ The means (SD) are unadjusted. * The number of alleles 2 (coded $0,1,2$ ) is used as a continuous variable and tested in a regression model with the variable in the left-hand column as dependent variable. The tests of linear trend are adjusted on population, there was no significant heterogeneity across population except for plasma CETP (see Table III). ${ }^{8}$ As a consequence of transportation or storage problems, only 78\% of the ECTIM controls had their plasma CETP measured. The mean plasma HDL cholesterol levels in 11, 12, and 22 individuals were 50.1 (SD 12.8), 51.3 (15.3), and $57.9(18.7) \mathrm{mg} / \mathrm{dl}$ (test of linear trend, $P<0.001)$ among those who had their plasma CETP measured and 47.1 (10.7), 50.5 (12.4), and 54.1 (13.3) $\mathrm{mg} / \mathrm{dl}(P<0.007)$ among those who did not have their plasma CETP measured.

the dependent variable was HDL cholesterol or CETP and the independent variables were the genotypes and alcohol consumption. The interaction term involving both independent variables was also tested.

Genotype frequencies were compared between cases and controls by logistic regression analysis, the independent variables were the genotypes and alcohol consumption. Here again the interaction between the two independent variables was tested. Odds-ratios and their $95 \%$ confidence intervals were computed from the logistic regression coefficients and their standard errors.

Since the ECTIM study consists of independent studies in four populations, homogeneity of the results in the different populations was tested and the statistical tests were adjusted on population. Homogeneity across population was checked by adding an independent term for population in the regression models and testing the interaction term involving population and genotypes and alcohol consumption. Most tables report results adjusted on population.

In the control groups, the genotype frequencies of the different polymorphisms were not significantly different from Hardy-Weinberg expectation.

\section{Results}

Lipid-related variables were first analyzed in the control group to avoid a potential bias resulting from post-MI changes. The frequency of the CETP/TaqIB 2 (B2) allele was similar in the four populations (40\%) and did not differ according to alcohol consumption. As shown in Table II, HDL related variables (HDL cholesterol, apolipoproteins AI and AII, LpAI and LpAI:AII) were associated with the CETP/TaqIB polymorphism $(P<0.001$, except for LpAI:AII, $P<0.05)$. The B2 allele was associated with an increased plasma concentration of these variables, especially in homozygotes. Lower plasma concentrations of CETP were observed in subjects carrying the B2 allele, with a dose effect $(P<0.0001)$. Conversely, no association was observed for the other lipid variables: LDL cholesterol and triglycerides (Table II), total and VLDL choles- terol, apoB, apoCIII, apoE, LpE:B, and LpCIII:B (not shown). Plasma HDL cholesterol and CETP were uncorrelated $(r$ $=-0.04, \mathrm{NS})$, this was true in individuals with genotypes B1B1 $(r=0.00$, NS), and B2B2 $(r=-.02)$ and the association between $\mathrm{B} 2$ and HDL related variables remained highly significant after adjustment on plasma CETP (Table II). The differences between genotypes were homogeneous across the four population samples included in the ECTIM study for all lipid variables except plasma CETP. As shown in Table III, the lack of homogeneity across populations for plasma CETP was principally due to a reduced genotypic effect in Strasbourg. Although a similar trend existed for HDL cholesterol, there was no significant lack of homogeneity of genotypic effect across populations for this variable.

The effect of B2 on HDL cholesterol was absent in nonalcohol drinkers but increased with alcohol consumption (Table IV), this heterogeneity of effect is reflected by the highly significant interaction $(P<0.0001)$. Among those individuals consuming 75 grams/d of alcohol or more, B1B2 heterozygotes and B2B2 homozygotes had, respectively, a 13 and $30 \%$ higher mean plasma HDL cholesterol level than B1B1 homozygotes. For the other HDL related variables, similar interactions between the B2 allele and alcohol consumption were observed (data not shown). Conversely, alcohol consumption had no effect on plasma CETP concentration whatever the genotype of CETP and the genetic effect on CETP concentration was not influenced by alcohol consumption (Table IV). The mean plasma HDL cholesterol levels according to alcohol consumption ( $<25$ grams/d vs. 25 grams/d or more) and CETP/TaqIB genotypes in the four populations of the ECTIM study are shown in Table V. No relationship between plasma HDL cholesterol and genotypes was observed in those consuming $<25$ grams/d of alcohol in any of the populations. Conversely in those consuming 25 grams/d of alcohol or more, higher mean levels of HDL cholesterol were observed in those carrying the 
Table III. Mean (SD) Levels of Plasma HDL Cholesterol and CETP in the Different Control Groups of the ECTIM Study

\begin{tabular}{|c|c|c|c|c|}
\hline CETP/TAqIB genotype & Belfast & Lille & Strasbourg & Toulouse \\
\hline \multicolumn{5}{|c|}{ HDL cholesterol (mg/dl) } \\
\hline \multirow[t]{2}{*}{11} & $n=60$ & $n=48$ & $n=68$ & $n=82$ \\
\hline & $51.6 \quad(13.7)$ & $51.0 \quad(12.0)$ & $48.9 \quad(13.8)$ & $47.7 \quad(10.3)$ \\
\hline \multirow[t]{2}{*}{12} & $n=86$ & $n=76$ & $n=96$ & $n=88$ \\
\hline & $49.0 \quad(14.4)$ & $54.4 \quad(17.9)$ & $50.8 \quad(14.5)$ & $50.8 \quad(11.8)$ \\
\hline \multirow[t]{2}{*}{22} & $n=32$ & $n=24$ & $n=27$ & $n=37$ \\
\hline & $56.8 \quad(16.4)$ & $64.7 \quad(21.7)$ & $51.9 \quad(13.9)$ & $55.2 \quad(16.1)$ \\
\hline \multicolumn{5}{|l|}{ CETP (mg/dl) } \\
\hline \multirow[t]{2}{*}{11} & $n=58$ & $n=46$ & $n=63$ & $n=35$ \\
\hline & $0.222(0.115)$ & $0.298(0.123)$ & $0.166(0.051)$ & $0.266(0.088)$ \\
\hline \multirow[t]{2}{*}{12} & $n=80$ & $n=67$ & $n=94$ & $n=36$ \\
\hline & $0.195(0.078)$ & $0.272(0.140)$ & $0.172(0.065)$ & $0.239(0.089)$ \\
\hline \multirow[t]{2}{*}{22} & $n=27$ & $n=20$ & $n=25$ & $n=13$ \\
\hline & $0.154(0.072)$ & $0.184(0.083)$ & $0.153(0.045)$ & $0.190(0.058)$ \\
\hline
\end{tabular}

ANOVA of HDL cholesterol: population (NS), CETP/TaqIB $(P<0.0001)$, interaction (NS). ANOVA of CETP: population $(P<0.0001)$, CETP/ TaqIB $(P<0.0001)$, interaction $(P<0.025)$.

B2 allele in the four populations; however, a significant interaction $(P<0.05)$ between genotypes and population was observed which reflected a weaker association in Strasbourg.

All of these analyses were also performed after exclusion of subjects treated with lipid-lowering drugs (6\% among con- trols ), the results were similar to those reported for the whole study group.

Comparisons of relevant characteristics in patients with MI and controls are provided in Table VI. Patients were 1 yr older $(P<0.05)$ and had a $16.5 \%$ lower plasma HDL cholesterol

Table IV. Mean (SD) Levels of Plasma HDL Cholesterol and CETP According to CETP Genotypes and Alcohol Consumption in Controls.

\begin{tabular}{|c|c|c|c|c|}
\hline \multirow{2}{*}{$\begin{array}{l}\text { Alcohol consumption } \\
\text { grams/d }\end{array}$} & \multicolumn{3}{|c|}{ CETP/TaqIB genotypes } & \multirow{2}{*}{$\begin{array}{c}\text { Test of } \\
\text { linear trend* }\end{array}$} \\
\hline & 11 & 12 & 22 & \\
\hline \multicolumn{5}{|c|}{ HDL cholesterol (mg/dl) ${ }^{\ddagger}$} \\
\hline \multirow[t]{2}{*}{0} & $n=36$ & $n=52$ & $n=15$ & \\
\hline & $48.3 \quad(12.7)$ & $48.7 \quad(13.5)$ & $46.3 \quad(10.0)$ & NS \\
\hline \multirow[t]{2}{*}{$>0<25$} & $n=83$ & $n=110$ & $n=36$ & \\
\hline & $49.9 \quad(13.9)$ & $48.4 \quad(12.8)$ & $51.9 \quad(14.1)$ & NS \\
\hline \multirow[t]{2}{*}{$\geqslant 25<50$} & $n=56$ & $n=78$ & $n=27$ & \\
\hline & $48.5 \quad(11.3)$ & $50.1 \quad(12.2)$ & $57.1 \quad(13.8)$ & $P<0.01$ \\
\hline \multirow[t]{2}{*}{$\geqslant 50<75$} & $n=43$ & $n=46$ & $n=17$ & \\
\hline & $49.3 \quad(9.0)$ & $52.6 \quad(17.8)$ & $60.9 \quad(22.1)$ & $P<0.02$ \\
\hline \multirow[t]{2}{*}{$\geq 75$} & $n=40$ & $n=60$ & $n=25$ & \\
\hline & $51.6 \quad(14.1)$ & $58.5 \quad(17.3)$ & $67.0 \quad(19.6)$ & $P<0.001$ \\
\hline \multicolumn{5}{|l|}{$\operatorname{CETP}(\mathrm{mg} / \mathrm{dl})^{\ddagger}$} \\
\hline 0 & $\begin{array}{c}n=31 \\
0.234(0.132)\end{array}$ & $\begin{array}{c}n=43 \\
0.236(0.098)\end{array}$ & $\begin{array}{c}n=10 \\
0.171(0.059)\end{array}$ & NS \\
\hline$>0<25$ & $\begin{array}{c}n=64 \\
0.207(0.089)\end{array}$ & $\begin{array}{c}n=91 \\
0.200(0.074)\end{array}$ & $\begin{array}{c}n=23 \\
0.168(0.060)\end{array}$ & $P<0.05$ \\
\hline$\geqslant 25<50$ & $\begin{array}{c}n=40 \\
0.226(0.103)\end{array}$ & $\begin{array}{c}n=62 \\
0.207(0.121)\end{array}$ & $\begin{array}{c}n=20 \\
0.177(0.065)\end{array}$ & $P<0.05$ \\
\hline$\geqslant 50<75$ & $\begin{array}{c}n=35 \\
0.260(0.130)\end{array}$ & $\begin{array}{c}n=35 \\
0.201(0.090)\end{array}$ & $\begin{array}{c}n=11 \\
0.143(0.064)\end{array}$ & $P<0.001$ \\
\hline$\geq 75$ & $\begin{array}{c}n=33 \\
0.241(0.101)\end{array}$ & $\begin{array}{c}n=46 \\
0.225(0.132)\end{array}$ & $\begin{array}{c}n=21 \\
0.165(0.083)\end{array}$ & $P<0.03$ \\
\hline
\end{tabular}

${ }^{\ddagger}$ The means are unadjusted. * The number of alleles 2 (coded $\left.0,1,2\right)$ is used as a continuous variable and tested in a regression model with HDL cholesterol (CETP) as dependent variable. The tests of linear trend within each class of alcohol consumption are adjusted on population. Global statistical analysis: regression analysis adjusted on population, the number of alleles 2 (coded $0,1,2$ ) and classes of alcohol consumption (coded $0,1,2,3,4$ for consumption of $0,>0<25, \geq 25<50, \geqslant 50<75$ and $\geq 75$, respectively) are used as continuous independent variables. HDL cholesterol:alcohol (NS), CETP/TaqIB (NS), interaction $(P<0.0001)$; CETP:alcohol (NS), CETP/TaqIB $(P<0.0001)$, interaction (NS). 
Table V. Mean (SD) Levels of Plasma HDL Cholesterol According to the CETP/TaqIB Genotypes and Alcohol Consumption in the Different Control Populations of the ECTIM Study

\begin{tabular}{|c|c|c|c|c|}
\hline CETP/TaqIB genotype & Belfast & Lille & Strasbourg & Toulouse \\
\hline \multicolumn{5}{|c|}{ Alcohol consumption $<25$ grams $/$ d } \\
\hline 11 & $n=37$ & $n=12$ & $n=32$ & $n=38$ \\
\hline & $52.2(16.4)$ & $51.4(11.9)$ & $47.3(13.2)$ & 47.9 (10.7) \\
\hline 12 & $\begin{array}{c}n=52 \\
46.3(13.0)\end{array}$ & $\begin{array}{c}n=19 \\
48.0(13.6)\end{array}$ & $\begin{array}{c}n=51 \\
50.2(14.9)\end{array}$ & $\begin{array}{c}n=40 \\
49.6(9.7)\end{array}$ \\
\hline 22 & $\begin{array}{c}n=14 \\
48.9(10.3)\end{array}$ & $\begin{array}{c}n=9 \\
50.0(16.1)\end{array}$ & $\begin{array}{c}n=11 \\
49.7(14.5)\end{array}$ & $\begin{array}{c}n=17 \\
51.8(13.6)\end{array}$ \\
\hline \multicolumn{5}{|c|}{ Alcohol consumption $\geq 25 \mathrm{grams} / \mathrm{d}$} \\
\hline 11 & $\begin{array}{c}n=23 \\
50.7(8.0)\end{array}$ & $\begin{array}{c}n=36 \\
50.9(12.2)\end{array}$ & $\begin{array}{c}n=36 \\
50.4(14.3)\end{array}$ & $\begin{array}{c}n=44 \\
47.5(10.1)\end{array}$ \\
\hline 12 & $\begin{array}{c}n=34 \\
53.2(15.7)\end{array}$ & $\begin{array}{c}n=57 \\
56.5(18.7)\end{array}$ & $\begin{array}{c}n=45 \\
51.6(14.3)\end{array}$ & $\begin{array}{c}n=48 \\
51.9(13.4)\end{array}$ \\
\hline 22 & $\begin{array}{c}n=18 \\
63.1(17.7)\end{array}$ & $\begin{array}{c}n=15 \\
73.5(20.7)\end{array}$ & $\begin{array}{c}n=16 \\
53.4(13.6)\end{array}$ & $\begin{array}{c}n=20 \\
58.0(17.7)\end{array}$ \\
\hline
\end{tabular}

ANOVA of plasma HDL cholesterol: alcohol consumption $<25$ grams/d: population (NS), CETP/TaqIB (NS), interaction (NS); alcohol consumption $\geq 25$ grams/d: population $(P<0.001)$, CETP/TaqIB $(P<0.0001)$, interaction (NS). In this group when the genotypes are tested as a $0,1,2$ ordinal variable, the results of the statistical analysis are: population (NS), CETP/TaqIB $(P<0.0001)$, interaction $(P<0.05)$.

level $(P<0.0001)$ than controls. Conversely, plasma CETP level was similar in both groups. Alcohol consumption in patients before MI was lower than in controls $(P<0.05)$; on the other hand, the cigarette consumption of cases before MI was much higher than that of controls $(P<0.0001)$. In MI patients (Table VII), the mean level of plasma CETP decreased with the number of $\mathrm{B} 2$ alleles $(P<0.008)$ as in the controls, whereas the effect of the polymorphism on plasma HDL cholesterol ( $P$ $<0.03$ ) was much weaker than in the controls (Table II, $P$ $<0.0001$ ). The simultaneous effect of the CETP/TaqIB polymorphism and alcohol consumption on plasma HDL cholesterol was not investigated in MI patients because alcohol consumption reflected consumption before MI, whereas HDL cholesterol was measured on plasma obtained 3-9 mo after the MI.

An association between the B2 allele and plasma HDL cholesterol in alcohol drinkers suggested that presence of this allele might be protective against CHD in this subgroup. The results

Table VI. Mean (SD) Values of Some Characteristics in Patients with MI and Controls

\begin{tabular}{lccccc}
\hline & & & & & $\begin{array}{c}\text { Test of } \\
\text { case-control } \\
\text { difference* }\end{array}$ \\
\hline$n$ & Patients with MI & Controls & \multicolumn{2}{c}{724} \\
Age & \multicolumn{2}{c}{608} & \multicolumn{2}{c}{7} & \\
$\begin{array}{l}\text { Alcohol consumption } \\
\quad \text { grams/d) }\end{array}$ & 54.0 & $(8.2)$ & 53.0 & $(8.5)$ & $P<0.05$ \\
$\begin{array}{l}\text { Cigarettes/d } \\
\text { HDL cholesterol }\end{array}$ & 34.1 & $(39.9)$ & 40.5 & $(42.0)$ & $P<0.05$ \\
$\quad(\mathrm{mg} / \mathrm{dl})$ & 11.5 & $(16.5)$ & 5.6 & $(10.6)$ & $P<0.0001$ \\
CETP (mg/dl) & 43.0 & $(11.4)$ & 51.5 & $(14.6)$ & $P<0.0001$ \\
\hline & $0.208(0.109)$ & $0.211(0.102)$ & NS \\
\hline
\end{tabular}

${ }^{\ddagger}$ Plasma CETP was measured in $78 \%$ of the patients and $70 \%$ of the controls. * Adjusted on population. reported in Table VIII are consistent with this hypothesis. The odds-ratio for MI in those carrying the B2B2 genotype decreased with increasing alcohol intake. The interaction term estimated in the logistic regression analysis involving presence/ absence of the genotype and alcohol consumption was significant $(P<0.034)$. The protective effect of B2B2 was significant only in the highest category of alcohol intake $(P<0.02$, oddsratio [95\% confidence interval]: $0.34[0.14-0.83])$ and was present in the high risk population of Belfast (odds-ratio: 0.28 [0.07-1.1]) as well as in France (odds ratio: 0.44 [0.141.39]). Adjustment on HDL cholesterol level induced a slight reduction of this association (odds-ratio: 0.47 [0.17-1.26]), while adjustment on CETP concentration did not (odds-ratio: $0.35[0.12-1.05])$.

The interaction between alcohol consumption and the CETP polymorphism on MI was also explored by computing oddsratios for MI associated with alcohol consumption $(<50$ grams/d vs. 50 grams/d or more) in the different CETP/TaqIB genotypes. The protective effect of alcohol consumption was weak and nonsignificant in B1B1 and B1B2 individuals (oddsratios: 0.72 and 0.81 , respectively) and stronger in $\mathrm{B} 2 \mathrm{~B} 2$ homozygotes $(P<0.005$, odds-ratio: $0.39[0.20-0.75])$.

No significant interaction between smoking status and CETP genotypes on lipid variables or MI risk was observed (Table IX).

Molecular screening of 6 B1 and 14 B2 alleles of the CETP gene revealed 3 noncoding polymorphisms in introns 7,12 , and 16 , respectively, but no coding polymorphism was found. The three variants were assayed in the whole ECTIM population. The intron 7 polymorphism was strongly associated with the TaqIB polymorphism; only $4.6 \%$ of the controls and $4.9 \%$ of the cases had nonconcordant genotypes. As a consequence, both polymorphisms provided similar results when analyzed in relation to plasma HDL cholesterol and CETP concentrations and MI risk (data not shown). The less frequent alleles of the intron 12 and intron 16 polymorphisms had a frequency of 0.35 and 0.14 , respectively. These polymorphisms, either considered sin- 


\begin{tabular}{lccccccc}
\hline & \multicolumn{5}{c}{ CETP/TaqIB genotypes } & $\begin{array}{c}\text { Test of linear trend } \\
\text { adjusted on population }\end{array}$ \\
\cline { 2 - 6 } & \multicolumn{2}{c}{11} & \multicolumn{2}{c}{12} & 22 & \\
\hline$n$ & \multicolumn{2}{c}{209} & \multicolumn{2}{c}{312} & 87 & NS \\
Age & 53.8 & $(8.0)$ & 53.6 & $(8.4)$ & 55.8 & $(8.2)$ & NS \\
Alcohol consumption (grams/d) & 35.5 & $(39.9)$ & 34.8 & $(41.4)$ & 28.7 & $(33.9)$ & NS \\
Cigarettes/d & 12.0 & $(16.2)$ & 11.4 & $(16.7)$ & 10.5 & $(16.7)$ & $P<0.03$ \\
HDL cholesterol (mg/d) & 42.1 & $(10.4)$ & 42.8 & $(12.1)$ & 45.7 & $(10.5)$ & $P<0.008$ \\
CETP (mg/dl) & $0.223(0.116)$ & $0.204(0.108)$ & $0.185(0.082)$ & \\
\hline
\end{tabular}

gly or in combination with the CETP/TaqIB polymorphism, were not associated with plasma lipid variables or MI risk (data not shown).

The IN14A and IN14T variants in intron 14 and the D442G variant in exon 15 which have been identified by Inazu et al. (26) were genotyped in the ECTIM study in 182 patients with MI ( 96 from Belfast and 86 from Strasbourg) and 184 controls ( 86 from Belfast and 91 from Strasbourg). Only one individual was heterozygous for IN14A, no variant could be identified for the other sites.

Table VIII. Distribution of CETP/TaqIB Genotypes in Patients and Controls According to Alcohol Consumption

\begin{tabular}{|c|c|c|c|c|}
\hline $\begin{array}{c}\text { Alcohol } \\
\text { consumption }\end{array}$ & СЕTP/TaqIB & Cases & Controls & $\begin{array}{l}\text { Odds-ratio (22 vs. } 11 \\
\left.+12^{*}[95 \% \mathrm{CI}]\right)\end{array}$ \\
\hline \multicolumn{5}{|l|}{ grams $/ d$} \\
\hline & 11 & 25 & 36 & \\
\hline \multirow[t]{3}{*}{0} & 12 & 52 & 52 & \\
\hline & 22 & 15 & 15 & $1.04(0.68-1.59)$ \\
\hline & 11 & 84 & 83 & \\
\hline \multirow[t]{3}{*}{$>0<25$} & 12 & 114 & 110 & \\
\hline & 22 & 36 & 36 & $0.97(0.58-1.61)$ \\
\hline & 11 & 48 & 56 & \\
\hline \multirow[t]{3}{*}{$\geqslant 25<50$} & 12 & 65 & 78 & \\
\hline & 22 & 21 & 27 & $0.96(0.51-1.81)$ \\
\hline & 11 & 19 & 43 & \\
\hline \multirow[t]{3}{*}{$\geqslant 50<75$} & 12 & 42 & 46 & \\
\hline & 22 & 7 & 17 & $0.56(0.22-1.47)$ \\
\hline & 11 & 33 & 40 & \\
\hline \multirow[t]{2}{*}{$\geq 75$} & 12 & 39 & 60 & \\
\hline & 22 & 8 & 25 & $0.34(0.14-0.83)^{\ddagger}$ \\
\hline
\end{tabular}

* Odds-ratios for MI were computed from the regression coefficients estimated in the logistic regression analysis of case/control status on CETP genotype (22 vs. $11+12)$ and alcohol consumption (coded as indicated in the legend of Table IV) and are adjusted on population. In the logistic regression analysis, the interaction term involving presence of genotype 22 and alcohol consumption was statistically significant: $P$ $=0.034 .{ }^{\ddagger} P<0.02$, no significant heterogeneity across center, the corresponding odds-ratios in Belfast and France were $0.28(0.07-1.1)$ and $0.44(0.14-1.39)$, respectively.

\section{Discussion}

This study of large representative samples confirms the already known relationship between the CETP/TaqIB polymorphism and plasma HDL cholesterol (14-18). It furthermore demonstrates an interaction between this polymorphism and alcohol intake, on plasma HDL cholesterol level and the risk of MI. The CETP/TaqIB polymorphism was also strongly related to plasma CETP concentration; however, the genetic effect of the polymorphism on HDL cholesterol was independent of its effect on CETP concentration. It has already been shown that plasma CETP concentration is more strongly associated with cholesterol in apoB-containing lipoproteins than with HDL cholesterol level (4). In agreement with these results, plasma CETP was correlated with LDL cholesterol $(r=0.12, P<0.004)$ but not with HDL cholesterol $(r=-0.04$, NS) in the controls of the ECTIM study.

Recently, Hannuksela et al. (18) investigated plasma CETP activity and HDL cholesterol level in relation to the CETP/ TaqIB polymorphism in heavy alcohol drinkers $(n=93)$ and controls $(n=82)$. In this study, the effects of the CETP/TaqIB polymorphism on plasma CETP activity and HDL cholesterol level were apparently stronger among the controls than among the heavy drinkers. This is in contradiction with the results of the ECTIM study in which the polymorphism was associated with plasma CETP level whatever the level of alcohol consumption and with plasma HDL cholesterol only in alcohol drinkers. The heavy drinkers in the Finnish study consumed 193 (SD 81) grams/d of alcohol whereas in the ECTIM study those

Table IX. Mean (SD) Levels of Plasma HDL Cholesterol and CETP According to CETP/TaqIB Genotypes and Smoking

\begin{tabular}{lcrcrc}
\hline & CETP/TaqIB & \multicolumn{2}{c}{ HDL cholesterol } & \multicolumn{2}{c}{ CETP } \\
\hline \multirow{4}{*}{ Nonsmokers } & & \multicolumn{1}{c}{$n$} & $m g / d l$ & \multicolumn{1}{c}{$n$} & $m g / d l$ \\
& 11 & 185 & $49.7(12.7)$ & 141 & $0.223(0.105)$ \\
& 12 & 236 & $50.7(13.4)$ & 187 & $0.209(0.095)$ \\
Smokers & 22 & 26 & $57.1(17.0)$ & 62 & $0.166(0.069)$ \\
& 11 & 73 & $49.1(11.9)$ & 61 & $0.243(0.117)$ \\
& 12 & 110 & $52.2(17.3)$ & 90 & $0.216(0.117)$ \\
& 22 & 34 & $56.1(18.2)$ & 23 & $0.167(0.064)$
\end{tabular}

ANOVA of HDL cholesterol: smoking (NS), CETP/TaqIB $(P<$ 0.0001 ), interaction (NS); CETP: smoking (NS), CETP/TaqIB $(P<$ 0.0001 ), interaction (NS). 
consuming 75 grams/d or more had a mean alcohol consumption of 113 (SD 32) grams/d. It is possible that heavy drinkers develop metabolic abnormalities which may mask or cancel the genetic effect, this might be an explanation for the difference between the two studies. In the Finnish study, the genetic effect on plasma HDL cholesterol and CETP was apparently stronger in nonsmokers than in smokers. A similar finding has been reported from another study (17). In ECTIM, the polymorphism influenced plasma HDL cholesterol and CETP similarly in smokers and nonsmokers (Table IX); we have no explanation for these discrepant results.

The CETP/TaqIB polymorphism affects the 277th nucleotide in the first intron of the CETP gene. This polymorphism is not likely to be functional and is probably a marker for one or several functional variants located within the CETP gene or its vicinity. The two variants that we have identified in introns 12 and 16 of the CETP gene can be excluded as putative functional candidates because they were unrelated to plasma HDL cholesterol and CETP and to MI. Conversely, the polymorphism identified in intron 7 was very tightly associated with the CETP/ TaqIB polymorphism and both polymorphisms exhibited similar relationships with the lipid phenotypes and MI. The intron 7 polymorphism affects the eighth base of intron 7 , and, although we cannot exclude from our data that this polymorphism is functional, it is not likely to affect the splicing of the CETP mRNA.

The CETP/TaqIB and CETP/IN7 polymorphisms may define a particular haplotype identified by B2 which is linked to at least two functional variants. One of these variants would affect plasma CETP concentration without influencing the metabolism of HDL and the risk of MI. Conversely, the other variant would affect HDL levels and MI risk and its expression could be modulated by alcohol consumption. In two studies $(15,18)$ the CETP/TaqIB polymorphism was associated with CETP activity, whereas it was not in another study (17). Freeman et al. (17) postulated that differences in activity could be seen only in extreme situations (i.e., hyperalphalipoproteinemia) and that in the general population changes in activity were not responsible for the relation between the CETP gene polymorphism and HDL levels. These results suggested that mutations of the CETP protein might influence its substrate specificity. The measurement of CETP mass (21) in the ECTIM study would probably not be influenced by differences in substrate specificity resulting from a sequence polymorphism of the CETP protein. However, the likelihood of frequent sequence changes in the protein is small given the absence of any variation in the coding sequence of $14 \mathrm{~B} 2$ alleles. Although the implication of a gene located in the vicinity of the CETP gene cannot be excluded, it is more probable that the functional variant(s) responsible for the effects observed on plasma HDL cholesterol is located in a region involved in the expression of the gene or the processing of its product.

The important role played by environmental factors in the modulation of the expression of the CETP gene is supported by experiments in which the human gene and its flanking regulatory sequences were transfected in mice (28). In these studies, hepatic CETP mRNA was markedly induced and plasma CETP mass and activity increased in response to a high cholesterol diet. In contrast, such modifications were not observed in mice in which the expression of the CETP gene was controlled by a nonspecific promoter. These results show that the natural flanking regions of the CETP gene contain elements that mediate the increased transcription of the gene in response to dietary cholesterol.

Given the strong effect of alcohol consumption on HDL cholesterol in B2B2 homozygotes, a commensurate inverse effect on plasma CETP concentration would have been expected. The fact that this was not observed could be due to a reduced catabolism of apoAI-containing lipoproteins, the main carriers of CETP, induced by alcohol consumption (29). It is known that lipolysis of VLDL by lipoprotein lipase stimulates the transfer of esterified cholesterol from HDL to VLDL (4) and that alcohol intake stimulates lipoprotein lipase $(30,31)$. A functional variant linked to the $\mathrm{B} 2$ allele, by interfering with the normal transcription of the CETP gene, might impair the increased transfer of cholesteryl esters from HDL to VLDL expected in response to lipolysis. Since plasma HDL cholesterol and CETP are uncorrelated, this phenomenon could take place in the postprandial state and/or locally, in the adipose tissue for example. It may be relevant to note that in an animal model the local adipose tissue CETP mRNA was more strongly related with plasma HDL cholesterol than with plasma CETP concentration (32), thus suggesting that local transfer activity may contribute to the plasma level of HDL cholesterol. These postulated mechanisms are highly speculative, however, and metabolic studies will be needed to resolve the issue.

In studies in Finland (33), and Sri Lanka (16), the CETP/ TaqIB polymorphism was not associated (33) or only weakly associated with HDL cholesterol (16) and no effect on coronary risk could be demonstrated. This may be due to the small sample size of these studies or to the low alcohol consumption in the populations concerned.

The stronger effect of the CETP polymorphism on LPAI than on LpAI:AII particles is consistent with the fact that CETP is mainly present in LpAI and absent from LpAI:AII (34). Furthermore, it is known that LpAI increases the efflux of cholesterol from cultured cells in vitro while LpAI:AII does not promote this effect (35). Thus, it has been proposed that LpAI could constitute the antiatherogenic fraction of HDL (35). The results of the ECTIM study are compatible with this hypothesis (19) and they suggest that CETP may play a role in determining the relative amount of $\mathrm{LpAI}$ and LpAI:AII in the plasma.

Recently, Inazu et al. (26) identified three variants of the CETP gene in the Japanese population, a $G$ to A substitution in intron 14 (IN14A), an insertion of a $T$ at position +3 from the exon 14 /intron 14 junction (IN14T), and a missense mutation within exon 15 (D442G). The percentage of subjects carrying the IN14A and D442G variants was 6.9 and $1.8 \%$, respectively, whereas IN14T was less frequent. Interestingly, these variants accounted for $10 \%$ of the variability of HDL cholesterol in a sample of Japanese subjects unselected for HDL cholesterol level. In the ECTIM study we genotyped 366 individuals for these polymorphisms, only 1 individual was heterozygote for IN14A, no variant could be identified for the other sites. It may be concluded that these variants, which are relatively frequent in the Japanese population, are very rare in Caucasians.

In conclusion, these data demonstrate an interaction between alcohol consumption and a frequent polymorphism of the CETP gene on plasma HDL cholesterol and the risk of MI. This interaction is of similar magnitude in the high risk population of Belfast and in France and apparently does not contribute to the difference in CHD frequency between the two countries. The protective variant linked to the $\mathrm{B} 2$ allele was not found on the coding sequence of the gene, so it is possibly located in a region involved in the regulation of the expression of the gene. 
Therefore, we may surmise that it acts by modifying the interaction of such a region with a trans-acting factor that may be modulated by alcohol consumption.

\section{Acknowledgments}

We thank Dr. M.-H. Delfau, C. Souriau, and P. Poulain for their contribution to this work. This work was supported by grants from the Squibb Laboratory, the Sandoz Laboratory, the British Heart Foundation, INSERM, the "Institut Pasteur-Lille," and the Groupement de Recherches et d'études sur les Génomes (GREG).

\section{References}

1. Gordon, D. J., J. L. Probstfield, R. J. Garrison, J. D. Neaton, W. P. Castelli, J. D. Knoke, D. R. Jacobs, Jr., S. Bangdiwala, and H. A. Tyroler. 1989. Highdensity lipoprotein cholesterol and cardiovascular disease. Four prospective American studies. Circulation. 79:8-15.

2. Gordon, D. J., and B. M. Rifkind. 1989. High-density lipoprotein. The clinical implications of recent studies. N. Engl. J. Med. 321:1311-1316.

3. Langer, R. D., M. H. Criqui, and D. M. Reed. 1992. Lipoproteins and blood pressure as biological pathways for effect of moderate alcohol consumption on coronary heart disease. Circulation. 89:910-915.

4. Tall, A. R. 1993. Plasma cholesteryl ester transfer protein. J. Lipid. Res. 34:1255-1274.

5. Editorial. 1991. Cholesteryl ester transfer protein. Lancet. 338:666-667.

6. Savolainen, M. J., M. Hannuksela, S. Seppänen, K. Kervinen, and Y. A. Kes̈aniemi. 1990. Increased high-density lipoprotein cholesterol concentration in alcoholics is related to low cholesteryl ester transfer protein activity. Eur. J. Clin. Invest. 20:593-599.

7. Välimäki, M., J. Kahri, K. Laitinen, S. Lahdenperä, T. Kuusi, C. Ehnolm, M. Jauhiainen, J. M. Bard, J. C. Fruchart, and M.-R. Taskinen. 1993. High density lipoprotein subfractions, apolipoprotein A-I containing lipoproteins, lipoprotein (a), and cholesteryl ester transfer protein activity in alcoholic women before and after ethanol withdrawal. Eur. J. Clin. Invest. 23:406-417.

8. Hannuksela, M., Y. L. Marcel, Y. A. Kesäniemi, and M. J. Savolainen. 1992. Reduction in the concentration and activity of plasma cholesteryl ester transfer protein by alcohol. J. Lipid Res. 33:737-744.

9. Hagiage, M., C. Marti, D. Rigaud, C. Senault, F. Fumeron, M. Apfelbaum, and A. Girard-Globa. 1992. Effect of a moderate alcohol intake on the lipoproteins of normotriglyceridemic obese subjects compared with normoponderal controls. Metab. Clin. Exp. 41:856-861.

10. Bhatnagar, D., P. N. Durrington, K. M. Channon, H. Prais, and M. I. Mackness. 1993. Increased transfer of cholesteryl esters from high density lipoproteins to low density and very low density lipoproteins in patients with angiographic evidence of coronary artery disease. Atherosclerosis. 98:25-32.

11. Brown, M. L., A. Inazu, C. B. Hesler, L. B. Agellon, C. Mann, M. E. Whitlock, Y. L. Marcel, R. W. Milne, J. Koizumi, H. Mabuchi, et al. 1989. Molecular basis of lipid transfer protein deficiency in a family with increased high-density lipoproteins. Nature (Lond.). 342:448-451.

12. Inazu, A., M. W. Brown, C. B. Hesler, L. B. Agellon, J. Koizumi, K. Takata, Y. Maruhama, H. Mabushi, and A. R. Tall. 1990. Increased high-density lipoprotein levels caused by a common cholesteryl-ester transfer protein gene mutation. N. Engl. J. Med. 323:1234-1238.

13. Takahashi, K., X.-C. Jiang, N. Sakai, S. Yamashita, K. Hirano, H. Bujo, H. Yamazaki, J. Kusunoki, T. Miura, P. Kussie, et al. 1993. A missense mutation in the cholesteryl ester transfer protein gene with possible dominant effects on plasma high density lipoproteins. J. Clin. Invest. 92:2060-2064.

14. Kondo, I., K. Berg, D. Drayna, and R. Lawn. 1989. DNA polymorphism at the locus for human human cholesteryl ester transfer protein (CETP) is associated with high density lipoprotein cholesterol and apolipoprotein levels. Clin. Genet. 35:49-56.

15. Freeman, D. J., C. J. Packard, J. Shepherd, and D. Gaffney. 1990. Polymorphisms in the gene coding for cholesteryl ester transfer protein are related to plasma high-density lipoprotein cholesterol and transfer protein activity. Clin. Sci. 79:575-581.

16. Mendis, S., J. Shepherd, C. J. Packard, and D. Gaffney. 1990. Genetic variation in the cholesteryl ester transfer protein and apolipoprotein A-I genes and its relation to coronary heart disease in a Sri Lankan population. Atherosclerosis. 83:21-27.

17. Freeman, D. J., B. A. Griffin, A. P. Holmes, G. M. Lindsay, D. Gaffney, C. J. Packard, and J. Shepherd. 1994. Regulation of plasma HDL cholesterol and subfraction distribution by genetic and environmental factors: associations between the TaqI B RFLP in the CETP gene and smoking and obesity. Arterioscler. Thromb. 14:336-344.

18. Hannuksela, M. L., M. J. Liinamaa, Y. A. Kesäniemi, and M. J. Savolainen. 1994. Relation of polymorphisms in the cholesteryl ester transfer gene to transfer protein activity and plasma lipoprotein levels in alcohol drinkers. Atherosclerosis. 110:35-44.

19. Parra, H. J., D. Arveiler, A. E. Evans, J.-P. Cambou, P. Amouyel, A. Bingham, D. McMaster, P. Schaffer, P. Douste-Blazy, G. Luc, et al. 1992. A case-control study of lipoprotein particles in two populations at contrasting risk for CHD, the ECTIM Study. Arterioscler. Thromb. 12:701-707.

20. WHO MONICA Project Principal Investigators. 1988. The World Health Organization MONICA project (MONItoring trends and determinants in CArdiovascular disease ): a major international collaboration. J. Clin. Epidemiol. 41:105114

21. Mezdour, H., I. Kora, H. J. Parra, A. Tartar, Y. L. Marcel, and J. C. Fruchart. 1994. Two-site enzyme immunoassay of cholesteryl ester transfer protein with monoclonal and polyclonal antibodies. Clin. Chem. 40:593-597.

22. Saiki, R. K., D. H. Gefland, S. Stoffel, S. J. Scahrf, R. Higuchi, G. T. Horn, K. B. Mullis, and H. A. Herlich. 1988. Primer-directed enzymatic amplification of DNA with a thermostable DNA polymerase. Science (Wash. DC). 239:487-491.

23. Orita, M., H. Iwahana, H. Kanazawa, K. Hayashi, and T. Sekiya. 1989. Detection of polymorphisms of human DNA by gel electrophoresis as single strand conformation polymorphisms. Proc. Natl. Acad. Sci. USA. 86:2766-2770.

24. Poirier, O., S. Ricard, I. Behague, C. Souriau, A. E. Evans, D. Arveiler, P. Marques-Vidal, G. Luc, G. Roizes, and F. Cambien. 1995. Detection of new variants in the apolipoprotein B (ApoB) gene by PCR-SSCP. Hum. Mutat. In press.

25. Sanger F., S. Nicklen, and R. Coulson. 1977. DNA sequencing with chain terminating inhibitors. Proc. Natl. Acad. Sci. USA. 74:5463-5467.

26. Inazu, A., X. C. Jiang, T. Haraki, K. Yagi, N. Kamon, J. Koizumi, H. Mabushi, R. Takeda, K. Takata, Y. Moriyama, et al. 1994. Genetic cholesteryl ester transfer protein deficiency caused by two prevalent mutations as a major determinant of increased levels of high density lipoprotein cholesterol. J. Clin. Invest 94:1872-1882.

27. Di Lella, A. G., W. M. Huang, and S. L. C. Wood. 1988. Screening for phenyl-ketonuria mutation by amplification with the polymerase chain reaction. Lancet. 5:497-499.

28. Jiang, X. C., L. B. Agellon, A. Walsh, J. L. Breslow, and A. R. Tall. 1992. Dietary cholesterol increases transcription of the human cholesteryl ester transfer protein gene in transgenic mice: dependence on natural flanking sequences. J. Clin. Invest. 90:1290-1295.

29. Hojnacki, J. L. 1994. Alcohol's influence on plasma lipoproteins: a nonhuman primate model. Nutr. Res. 14:1241-1275.

30. Belfrage, P., B. Berg, I. Hägerstrand, P. Nilsson-Ehle, H. Tornquist, and T. Wiebe. 1977. Alteration of lipid metabolism in healthy volunteers during long term ethanol intake. Eur. J. Clin. Invest. 7:127-131.

31. Taskinen, M. R., M. Välimäki, E. A. Nikkilä, T. Kuusi, C. Ehnholm, and R. Ylikahri. 1982. High density lipoprotein subfractions and postheparin plasma lipases in alcoholic men before and after ethanol withdrawal. Metab. Clin. Exp. 31:1168-1174.

32. Jiang, X. L., P. Moulin, E. Quinet, I. J. Goldberg, L. K. Yacoub, L. B. Agellon, D. Compton, R. Schnitzer-Polokoff, and A. R. Tall. 1991. Mammalian adipose tissue and muscle are major sources of lipid transfer protein mRNA. $J$. Biol. Chem. 266:4631-4639.

33. Tenkanen, H., P. Koskinen, K. Kontula, K. Aalto-Seëal̈a, M. Mänttäri, V. Manninen, S.-L. Runeberg, M.-R. Taskinen, and C. Ehnholm. 1991. Polymorphisms of the gene encoding cholesterol ester transfer protein and serum lipoprotein levels in subjects with and without coronary heart disease. Hum. Genet. 87:574-578.

34. Cheung, M. C., A. C. Wolf, K. D. Lum, J. H. Tollefson, and J. J. Albers. 1986. Distribution and localization of lecithin:cholesterol acyltransferase and cholesteryl ester transfer activity in A-I-containing lipoproteins. J. Lipid Res. 27:1135-1144.

35. Fruchart, J.-C., and G. Ailhaud. 1992. Apolipoprotein AI-containing lipoprotein particles: physiological role, quantification, and clinical significance. Clin. Chem. 38:793-797. 